\title{
Surgical treatment of traumatic cervical facet dislocation: anterior, posterior or combined approaches?
}

\author{
Deslocamentos facetários cervicais traumáticos: abordagem anterior, posterior ou combinada?
} Catarina C. Lins', Diego T. Prado², Andrei F. Joaquim ${ }^{1,3}$

\begin{abstract}
Surgical treatment is well accepted for patients with traumatic cervical facet joint dislocations (CFD), but there is uncertainty over which approach is better: anterior, posterior or combined. We performed a systematic literature review to evaluate the indications for anterior and posterior approaches in the management of CFD. Anterior approaches can restore cervical lordosis, and cause less postoperative pain and less wound problems. Posterior approaches are useful for direct reduction of locked facet joints and provide stronger fixation from a biomechanical point of view. Combined approaches can be used in more complex cases. Although both anterior and posterior approaches can be used interchangeably, there are some patients who may benefit from one of them over the other, as discussed in this review. Surgeons who treat cervical spine trauma should be able to perform both procedures as well as combined approaches to adequately manage CFD and improve patients' final outcomes.
\end{abstract}

Keywords: spine; dislocations; bones fractures; surgery.

\section{RESUMO}

O tratamento dos deslocamentos facetários cervicais traumáticos (DFC) é preferencialmente cirúrgico, conforme a literatura pertinente, mas há dúvidas quanto a melhor forma de abordagem da coluna: anterior, posterior ou combinada. Realizamos revisão sistemática para avaliar as indicações da abordagem anterior e da posterior nos DFC. A abordagem anterior permite restaurar a lordose cervical, com menor dor no pós-operatório e menos problemas relacionados a ferida cirúrgica. A abordagem posterior permite redução direta dos deslocamentos, bem como pode resultar em uma fixação biomecanicamente mais robusta. Acessos combinados são usados em casos complexos. Embora ambas possam ser usadas, há alguns pacientes que possivelmente se beneficiem preferencialmente de uma abordagem ao invés da outra, como discutido no presente manuscrito. Cirurgiões de coluna devem ser habilitados a realizar ambos os procedimentos para melhor os resultados do tratamento dos DFC.

Palavras-chave: coluna vertebral; luxações; fraturas ósseas; cirurgia.

Anatomically, the cervical spine can be divided in two distinct regions: the craniovertebral junction, from the occiput joint to the axis, and the subaxial cervical spine, which encompass injuries from $\mathrm{C} 3$ to $\mathrm{C} 7^{1,2,3}$. About $50 \%$ of all cervical spine injuries are located between $\mathrm{C} 5$ and $\mathrm{C} 7$, the most affected segment ${ }^{3}$.

Cervical spine injuries are common as a result of a growing number of high energy accidents. Surgical treatment of subaxial cervical spine injuries is important for restoration and protection of the spinal cord and nerve roots, reestablishing cervical alignment and also to restore spinal stability ${ }^{1}$.
Unilateral and bilateral facet dislocations are quite common in the setting of subaxial cervical trauma. Considering the neurological status in unilateral facet dislocations, $25 \%$ of the patients are neurologically intact, $37 \%$ have radicular deficits, $22 \%$ have incomplete deficits and about $15 \%$ are tetraplegic ${ }^{4}$. Bilateral facet dislocation is associated with significant soft tissue damage and a higher incidence of neurological deficits compared with unilateral facet dislocation ${ }^{4}$. These lesions are highly unstable and early reduction is recommended to decompress the spine and improve neurological outcomes ${ }^{5,6,7,8,9,10,11}$.

${ }^{1}$ Hospital Municipal Dr. Mário Gatti, Divisão de Neurocirurgia, Campinas SP, Brasil;

${ }^{2}$ Universidade de São Paulo, Faculdade de Medicina, Hospital das Clínicas, Departamento de Otorrinolaringologia, São Paulo SP, Brasil;

${ }^{3}$ Universidade Estadual de Campinas, Departamento de Neurologia, Campinas SP, Brasil.

Correspondence: Andrei F. Joaquim; Departamento de Neurologia, Universidade Estadual de Campinas; Cidade Universitária Zeferino Vaz; $13090-610$ Campinas SP, Brasil; E-mail: andjoaquim@yahoo.com

Received 27 January 2016; Accept 18 April 2016. 
Although the literature supports that both anterior and posterior stabilization have similar clinical outcomes with good surgical results, there are advantages and disadvantages of one over the other in the management of facet dislocations ${ }^{8,9}$.

In an attempt to provide evidence of the best management of cervical facet dislocation (CFD), we performed a systematic literature review of the treatment of these injuries, discussing the surgical indications of the anterior and posterior approaches.

\section{METHODS}

A manual search in the PubMed database for articles based on following keywords was performed: "dislocation", "fracture", "cervical spine", "anterior", "posterior", "treatment", and "surgery". Only articles about subaxial cervical spine (C3 to C7) were included, when discussing treatment of cervical spine facet dislocation and advantages of each approach. We also searched for articles comparing the clinical outcome of anterior vs posterior cervical spine fixation for treating facet dislocation. There was no time restriction for the search. Clinical articles as well as literature reviews were included if they discussed the treatment of facet joint dislocation.

\section{Study quality assessment}

The level of evidence of the selected studies was classified according to the criteria adopted by the North American Spine Society, adapted from the Oxford Centre for EvidenceBased Medicine ${ }^{12}$ :

1) Level I: High quality randomized trial or prospective study; testing of previously developed diagnostic criteria on consecutive patients; sensible costs and alternatives; values obtained from many studies with multiway sensitivity analyses; systematic review of Level I randomized controlled trials (RCTs) and Level I studies.

2) Level II: Lesser quality (RCT); prospective comparative study; retrospective study; untreated controls from an RCT; lesser quality prospective study; development of diagnostic criteria in consecutive patients; sensible costs and alternatives; values obtained from limited studies; with multiway sensitivity analyses; systematic review of Level II studies or Level I studies with inconsistent results.

3) Level III: Case control study (therapeutic and prognostic studies); retrospective comparative study; study of nonconsecutive patients without consistently applied reference "gold" standard; analyses based on limited alternatives and costs, and poor estimates; systematic review of Level III studies.

4) Level IV: Case series; case control study (diagnostic studies); poor reference standard; analyses with no sensitivity analyses.

5) Level V: Expert opinion.

\section{RESULTS}

Initial treatment of patients with spinal cord injury (SCI) includes the ABCDE protocols of the Advanced Trauma Life Support ${ }^{\circledR}{ }^{13}$. After clinical screening and patient stabilization, the radiological diagnosis of cervical spinal trauma is made, preferably with a 3D computed tomography (CT) scan with triplanar reconstruction and complemented with magnetic resonance imaging (MRI) when necessary ${ }^{1,3}$. Once the radiological diagnosis of a CFD is made, early reduction may be advisable to avoid additional injury or even improve neurological outcome when SCI is present. According to the results of the Surgical Timing in Acute Spinal Cord Injury Study (STASCIS), a multicenter international prospective cohort study, early reduction (with traction or early surgery $-<24$ hours) indicated a higher rate of neurological improvement compared with late decompression ( $>24$ hours). A total of 182 patients had early surgery compared with 131 patients with late procedures ${ }^{14}$. After six months, $19.8 \%$ of the patients in the early group had at least a 2 grade improvement on the American Spine Injury Association Impairment Scale compared with $8.8 \%$ rate of improvement in the late decompression group (odds ratio - 2.57, 95\% confidence interval: 1.11 to 5.97$)^{14}$. According to this study, early decompression added no increase in complication, with a more favorable neurological outcome (Level of Evidence: II) ${ }^{14}$.

Cervical facet joint dislocation is generally managed surgically. The Subaxial Injury Classification System and Severity Score (SLICS) suggests that a unilateral or bilateral facet dislocation must be managed surgically, even in the absence of SCI (Level of Evidence: III) ${ }^{10,11,15}$. Conservative management is associated with a high incidence of recurrent instability and

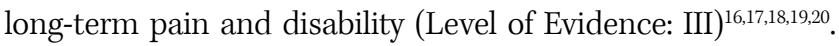
Thus, surgical fixation has become increasingly favored for unilateral facet lesions, particularly those that are displaced (Level of Evidence III) $)^{16,17,18,19,20}$. In patients with cervical dislocations, early closed traction may play a role in the treatment, since up to $70 \%$ of the dislocations can thereby be reduced with external traction (Level of Evidence: III) ${ }^{16,17,18,19}$. Although the benefits of preoperative traction and reduction compared to open reduction need further studies, this treatment modality may provide early decompression of the neural tissue and also facilitate surgery, especially in centers where spine surgeons are not available full time. A cervical spine MRI may be obtained prior to the procedure to rule out a cervical disc herniation, but traction can be safely performed in awake patients with close clinical monitoring of the neurological status even without a cervical MRI (Level of Evidence: III) ${ }^{4,5}$. Typically, the initial weight is $2.5 \mathrm{~kg} /$ per injury level and can be performed in neutral, flexion or extension position, according to injury characteristics ${ }^{1,21}$. The patient should be followed clinically and radiologically (with lateral cervical radiography performed in the bed) until reduction is obtained. The main purpose of traction is to obtain and maintain closed reduction in lateral cervical 
spine radiography. The risks of the procedure include over distraction and neurological deterioration secondary to compression of the spinal cord over an unnoticed herniated disc or a bone fragment. The technique is done with the patient in a supine neutral position and infiltration after local asepsis, and is best performed in an intensive care unit with a specific bed for traction. The pins are then positioned just below the superior temporal line, avoiding the temporal muscle and the temporal artery. To obtain flexion or extension, they may be placed asymmetrically, which can be especially useful for unilateral dislocations. Flexion and contralateral rotation are recommended for closed reduction of unilateral facet dislocation. Once the reduction is achieved, it must be kept in traction-inline with weights from 7.5 to 10 kilograms, and some degree of extension, until definitive surgical fixation. This procedure is not recommended in patients whose examination is unreliable (such as obtunded patients or those who are in a coma) and in those with distractive injuries such as atlantoaxial or occipto-cervical dislocation ${ }^{1,22}$.

\section{Anterior cervical approaches}

\section{Advantages and indications}

Anterior approaches can maintain or restore cervical lordosis and also may cause less postoperative pain than posterior cervical surgeries (Level of Evidence: III). ${ }^{23}$ Anterior approaches have the advantages of supine position, less surgical trauma, and direct anterior decompression of neural elements, such as a disk herniation or an anterior located bone fragment (Level of Evidence: III) ${ }^{23}$.

Kwon et al. reported that patients treated with anterior cervical discectomy and fusion (ACDF) for unilateral facet fracture-dislocation had slightly less pain in the postoperative period, a lower rate of wound infection, a higher rate of radiological bone union, with a better cervical alignment compared with those treated with a posterior approach (Level of Evidence: II) 9 .

An anterior cervical approach is recommended for a disc herniation in patients without a complete neurological deficit as it allows direct decompression, avoiding neurological deterioration with an eventual indirect decompression achieved with a posterior laminectomy $y^{1,15,24}$. In the past, this was an absolute indication for an anterior approach, but Nakashima et al. reported a series of 40 patients with traumatic cervical herniation treated by a posterior approach without need of anterior cervical surgery, suggesting that the risk of neurological deterioration may be less than reported previously (Level of Evidence: III) ${ }^{23}$.

Many different surgical techniques have been described to reduce facet dislocations using an anterior approach ${ }^{6}$. After disk and posterior ligament resection, distractor pins are inserted. Distractor placement results in local kyphosis, unlocking the posterior facet joints with some additional posterior force applied to the vertebral body. In unilateral dislocation, the pins are placed in a similar fashion but with additional coronal separation to open room for rotation. After distraction, which may release the facet joints, some gentle posterior force may be applied in the rostral vertebral body, reducing the locked joint and recovering articular congruence $^{1,6}$. An alternative maneuver for reducing a locked facet joint is continuous intraoperative external cranial traction. After disc removal, the use of a Cobb elevator in the interbody space can also be utilized to move away the dislocated facets, making the reduction easier. Most of the time, anterior cervical discectomy and interbody fusion are sufficient to remove the disk fragment present in the canal, even when some caudal or cranial migration is present ${ }^{1,6}$.

If the dislocation could not be reduced after an anterior approach, the patient must be turned prone with a direct partial facetectomy, reduction and subsequent posterior fixation. An additional anterior procedure may offer a stronger fixation in such cases and should be considered at the surgeon's discretion, potentially restoring the loss of disc space and maintaining some degree of cervical lordosis.

\section{Contra-indications and disadvantages}

Potential disadvantages may include postoperative dysphagia, esophageal injury and difficulty in achieving facet reduction in some cases, especially chronic dislocations (Level of Evidence: III $)^{1,16,17,19}$. Postoperative dysphagia is related to manipulation and retraction of the esophagus during cervical procedures. ${ }^{23}$ Therefore, procedures with extended dissection, longer duration of surgery, multilevel spinal fusion, and postoperative pre-vertebral thickness, increase the risk of postoperative dysphagia ${ }^{23}$. This may be due to intraluminar esophageal pressure and esophageal mucosal ischemia ${ }^{23}$. Dysphagia has also been considered to be caused by the plate prominence and thickness ${ }^{23}$. Some other factors that may result in swallowing dysfunction after cervical spine surgery are pain, muscle spasm and immobilization in a cervical collar. Furthermore, dysphagia may be present before surgery due to osteophytes of the vertebral bodies ${ }^{23}$. Esophageal injuries are catastrophic and early surgical consultation is recommended, keeping patients on fast until an esophageal surgeon evaluates the patient.

In general, the surgical results of anterior cervical spine surgeries are perceived to be favorable. However, difficulties in reduction and in securing rigid fixation are the main drawbacks ${ }^{22,24}$.

A potential problem after ACDF is postoperative kyphosis. Johnson et al. performed a radiological review of 87 patients with unilateral or bilateral dislocations with facet or fracture/dislocation treated with anterior cervical discectomy, fusion, and plating ${ }^{25}$. They reported a loss of postoperative cervical alignment in $13 \%$ of patients with fracture facet subluxation treated by ACDF due to mechanical failure of posterior elements, especially in distractive lesions (Level of Evidence: III $)^{24}$. Concern about the mechanical failure 
of flexion/distraction injuries should be high when they are associated with fractures of both facets and endplate. Endplate fracture was associated with both mechanical failure and nonunion ${ }^{24}$. Using longer screws and prescribing a rigid cervical collar may be useful in more unstable cases to avoid postoperative kyphosis after ACDF for treating CFD.

\section{Posterior cervical approaches}

\section{Indications and advantages}

Posterior approaches, on the other hand, may provide direct reduction of dislocations and stronger constructions, which can be interesting for patients with poor bone quality, such as those with ankylosing spondylitis or osteoporosis (Level of Evidence: III) $)^{15,16,18}$. Although there is little data about the incidence of dysphagia after posterior approaches, Radcliff et al. compared the incidence of dysphagia after posterior vs anterior cervical approaches ${ }^{26}$. They reported that the posterior surgeries had an incidence of $11 \%$ compared with $61.5 \%$ after an anterior cervicotomy (Level of Evidence: III $)^{26}$. However, posterior approaches may add some risk of neurological deterioration in patients with anterior compression and at least some degree of neurological preservation. Posterior approaches are less likely to restore cervical lordosis than anterior approaches and absence of a normal cervical alignment may have a negative influence in the long term outcome (Level of Evidence: III) ${ }^{15,22}$.

Posterior approaches based on rigid fixation techniques with lateral mass screws or pedicular screws are a good alternative for treating distractive and rotation injuries using reduction maneuvers that can be applied directly to realign the spine ${ }^{5,6,7,27}$. Additionally, patients with posterior bone compression associated with facet dislocation, such as a lamina fragment into the canal, can be managed successfully using a posterior approach.

Duggal et al. ${ }^{21}$ conducted a study where unilateral facet dislocation was created in the cervical spine of human cadavers. The specimens were instrumented sequentially with screws and plates, and studied to determine the biomechanical differences between the anterior and posterior fixation and the stabilization of a unilateral facet cervical dislocation reduction. It was found that lateral mass plating was more effective in limiting motion than anterior plating in unilateral facet dislocation.

\section{Contra-indications and disadvantages}

Posterior reduction of a CFD is a relative contra-indication in patients with an anterior spinal cord compression, such as a disc herniation, with an intact or residual neurological function, given the risk of deterioration during the reduction maneuver ${ }^{4,21}$. Clinically unstable patients may also have problems with an operation in the prone position, as well as an increased risk of wound complications compared with anterior surgery ${ }^{9}$.
Combined cervical approaches (antero-posterior, postero-anterior or even postero-antero-posterior or antero-postero-anterior approaches)

\section{Indications and advantages}

The combined approach provides the strongest fixation, significantly limiting motion ${ }^{5,7}$. A combined fixation for cervical dislocation increases the fusion rate, although without the additional advantage for neurological recovery (Level of Evidence: III $)^{28}$. A combined approach may be considered for patients with chronic injuries associated with pseudoarthrosis or cervical misalignment, when an osteotomy may be required to restore cervical alignment and neural decompression. Patients with poor bone quality, such as those with osteoporosis, ankylosing spondylitis or other chronic conditions, may also be candidates for a combined approach.

\section{Contra-indications and disadvantages}

In our search, we could not find any absolute contraindication for a combined approach. However, benefits of a combined approach must be weighed against the risk of an additional surgery and increasing morbidity related to each approach as well as increasing surgical costs.

\section{DISCUSSION}

The choice of anterior, posterior or a combined cervical approach is important for the treatment of traumatic CFD. Although good surgical outcomes can be obtained with all techniques, there are specific situations in which one may preferentially be used instead of the other. Although based on expert opinion and poor evidence studies, some authors recommended that the best approach is chosen based on the site of spinal cord compression, the presence of additional bone fracture (in the vertebral body or in the posterior bone elements) and the surgeon(s) preference/expertise $\mathrm{e}^{1,4,5,6,7}$. When a posterior cervical approach is planned, a preoperative MRI is recommended to evaluate a relevant disc herniation and anterior cord compression. In such cases, an anterior approach would be preferable.

We found only two studies comparing anterior vs posterior approaches for CFD. Brodke et al. ${ }^{8}$ compared the outcome of 52 consecutive patients with unstable cervical spine injuries who were randomly chosen to receive anterior vs posterior stabilization and fusion. Patients who were neurologically intact or with only cervical radiculopathy, or patients who required a specific approach for reduction or decompression were excluded. The authors reported no significant differences in neurological recovery, fusion rates or longterm complaints in both chosen approaches ${ }^{8}$. There were no differences in patient-reported outcome measures. The authors concluded that either prior or subsequent fixation approaches are valid and secure techniques for the treatment of cervical dislocation ${ }^{8}$. Similarly, Kwon et al. performed a 
prospective randomized controlled study using 42 patients with unilateral facet fracture, dislocation, or fracture-dislocation between C3 and T1 levels ${ }^{9}$. Patients underwent an ACDF or posterior fixation (Level of Evidence: II). They concluded that both techniques were effective and had similar outcomes, even though patients who underwent anterior surgery had a higher rate of fusion and less postoperative pain and wound problems than patients treated with a posterior approach. Both studies suggested the safety of anterior and posterior approaches to treat cervical dislocations.
In conclusion, although both anterior and posterior approaches can be used interchangeably for treating CFD, the evidence suggesting the superiority of one over the other is low. There are some clinical and radiological situations that indicate one approach may be preferentially used over the other. Considering that the level of evidence of the best treatment of cervical facet dislocations is inconclusive, surgeons who treat cervical spine trauma should be able to perform both procedures as well as combined approaches to adequately manage their patients and improve final outcomes.

\section{References}

1. Joaquim AF, Patel AA. Subaxial cervical spine trauma: evaluation and surgical decision-making. Global Spine J. 2013;4(1):63-70. doi:10.1055/s-0033-1356764

2. Torretti JA, Sengupta DK. Cervical spine trauma. Indian J Orthop. 2007;41(4):255-67. doi:10.4103/0019-5413.36985

3. Joaquim AF, Lawrence B, Daubs M, Brodke D, Patel AA. Evaluation of the subaxial injury classification system. J Craniovertebr Junction Spine. 2011;2(2):67-72. doi:10.4103/0974-8237.100057

4. AndreshakJL, Dekutoski MB. Management of unilateral facet dislocations: a review of the literature. Orthopedics. 1996;20(10):917-26.

5. Bartels RH, Donk R. Delayed management of traumatic bilateral cervical facet dislocation: surgical strategy: report of three cases. J Neurosurg. 2002;97(3):362-5. doi:10.3171/spi.2002.97.3.0362

6. Ordonez BJ, Benzel EC, Naderi S, Weller, SJ. Cervical facet dislocation: techniques for ventral reduction and stabilization. $J$ Neurosurg. 2000;92(1):18-23. doi:10.3171/spi.2000.92.1.0018

7. An HS. Cervical spine trauma. Spine. 1998;23(24):2713-29. doi:10.1097/00007632-199812150-00011

8. Brodke DS, Anderson PA, Newell DW, Grady MS, Chapman JR. Comparison of anterior and posterior approaches in cervical spinal cord injuries. J Spinal Disord Tech. 2003;16(3):229-35. doi:10.1097/00024720-200306000-00001

9. Kwon BK, Fisher CG, Boyd, MC, Cobb J, Jebson H, Noonan V et al. A prospective randomized controlled trial of anterior compared with posterior stabilization for unilateral facet injuries of the cervical spine. J Neurosurg Spine, 2007;7(1):1-12. doi:10.3171/SPI-07/07/001

10. Cruz HY, Joaquim AF, Tedeschi H, Patel AA. Evaluation of the SLICS use in the treatment of subaxial cervical spine injuries. Arq Neuropsiquiatr. 2015;73(5):445-9. doi:10.1590/0004-282X20150022

11. Joaquim AF, Ghizoni E, Tedeschi H, Cruz HY, Patel AA. Clinical results of patients with subaxial cervical spine trauma treated according to the SLIC score. J Spinal Cord Med. 2014;37(4):420-4. doi:10.1179/2045772313Y.0000000143

12. Howick J,Chalmers I, Glasziou P, Greenhalgh T, Heneghan C, Liberati A et al. The 2011 Oxford CEBM levels of evidence: introductory document. Oxford: Oxford Centre for Evidence-Based Medicine; 2011.

13. Tchorz KM. Advanced Trauma Life Support (ATLS®): the ninth edition. J Trauma Acute Care Surg. 2013;74(5):1363-6. doi:10.1097/TA.0b013e31828b82f5

14. Fehlings MG, Vaccaro A, Wilson JR, Singh A, Cadotte DW, Harrop JS et al. Early versus delayed decompression for traumatic cervical spinal cord injury: results of the Surgical Timing in Acute Spinal Cord Injury Study (STASCIS). PLoS One. 2012;7(2):e32037. doi:10.1371/journal.pone.0032037

15. Dvorak MF, Fisher CG, Fehlings MG, Rampersaud YR, Oner FC, Aarab B et al. The surgical approach to subaxial cervical spine injuries: an evidence-based algorithm based on the SLIC classification system. Spine. 2007;32(23):2620-9. doi:10.1097/BRS.0b013e318158ce16
16. Hadley MN, Fitzpatrick BC, Sonntag VK, Browner CM. Facet fracture-dislocation injuries of the cervical spine. Neurosurgery. 1992;30(5):661-6. doi:10.1227/00006123-199205000-00001

17. Bucholz RD, Cheung KC. Halo vest versus spinal fusion for cervical injury: evidence from an outcome study. J Neurosurg. 1989;70(6):884-92. doi:10.3171/jns.1989.70.6.0884

18. Halliday AL, Henderson BR, Hart BL, Benzel EC. The management of unilateral lateral mass/facet fractures of the subaxial cervical spine: the use of magnetic resonance imaging to predict instability. Spine. 1997;22(22):2614-21. doi:10.1097/00007632-199711150-00007

19. Rorabeck CH, Rock MG, Hawkins RJ, Bourne RB. Unilateral facet dislocation of the cervical spine: an analysis of the results of treatment in 26 patients. Spine. 1987;12(1):23-7. doi:10.1097/00007632-198701000-00004

20. Sears W, Fazl M. Prediction of stability of cervical spine fracture managed in the halo vest and indications for surgical intervention. J Neurosurg. 1990;72(3):426-32. doi:10.3171/jns.1990.72.3.0426

21. Duggal N, Chamberlain RH, Park SC, Sonntag VK, Dickman CA, Crawford NR. Unilateral cervical facet dislocation: biomechanics of fixation. Spine. 2005;30(7):E164-8. doi:10.1097/01.brs.0000157418.20900.a1

22. Aebi M. Surgical treatment of upper, middle and lower cervical injuries and non-unions by anterior procedures. Eur Spine J. 2010;19(Suppl 1):S33-9. doi:10.1007/s00586-009-1120-8

23. Nakashima H, Yukawa Y, Ito K, Machino M, Zahlawy H, Kato F. Posterior approach for cervical fracture-dislocations with traumatic disc herniation. Eur Spine J. 2011;20(3):387-94. doi:10.1007/s00586-010-1589-1

24. Johnson MG, Fisher CG, Boyd M, Pitzen T, Oxland TR, Dvorak MF. The radiographic failure of single segment anterior cervical plate fixation in traumatic cervical flexion distraction injuries. Spine. 2004;29(24):2815-20. doi:10.1097/01.brs.0000151088.80797.bd

25. Joaquim AF, Murar J, Savage JW, Patel AA. Dysphagia after anterior cervical spine surgery: a systematic review of potential preventative measures. Spine J. 2014,14(9):2246-60. doi:10.1016/j.spinee.2014.03.030

26. Radcliff KE, Koyonos L, Clyde C, Sidhu GS, Fickes M, Hilibrand AS et al. What is the incidence of dysphagia after posterior cervical surgery? Spine. 2013;38(13):1082-8. doi:10.1097/BRS.0b013e318287ec9f

27. Abumi K, Shono Y, Kotani Y, Kaneda K. Indirect posterior reduction and fusion of the traumatic herniated disc by using a cervical pedicle screw system. J Neurosurg. 2000;92(1):30-7.

28. Song KJ, Lee KB. Anterior versus combined anterior and posterior fixation/fusion in the treatment of distraction-flexion injury in the lower cervical spine. J Clin Neurosci. 2008;15(1):36-42. doi:10.1016/j.jocn.2007.05.010 